\title{
Sonar system offered special dispensation
}

\section{Mark Schrope}

The US government is proposing to waive environmental laws so as to enable the Navy to deploy a controversial sonar system for submarine detection. The sonar has been the subject of intense debate because of its potentially adverse effects on marine mammals.

The Surveillance Towed Array Sensor System, with a Low Frequency Active upgrade, listens for reflections bouncing off submarines in response to bursts of sound emitted by the system. The Navy says the system is needed because modern submarines are too quiet to be detected by passive systems. The sonar has so far been fitted on only one ship, but the Navy has funding for a second and hopes to build two more to obtain global coverage.

Tests on the system were classified information until about six years ago, when environmentalists learned about it. They threatened the Navy with lawsuits based on concerns that it might cause hearing loss or disorientation in marine mammals. The Navy responded by agreeing to assess the system's environmental effects. It also supported additional research on the sonar's effects on the animals.

The research found that the system might significantly affect the mammals by, among other things, altering their migration patterns. Two recent whale strandings have also been linked to sonar use, although the Navy says these events involved factors, such as proximity to land, that would not apply to their plans for deploying the system.

Based on the assessment and related research, the National Marine Fisheries Service (NMFS), part of the National Oceanic and Atmospheric Administration, has just released a draft of a new rule that would give the Navy a five-year exemption from the Marine Mammal Protection Act. The act prohibits the harassment or killing of marine mammals by US entities in or outside US waters.

The rule outlines mitigation measures that the Navy and the NMFS say will ensure that the system has little effect on marine mammal populations. They include a promise not to use the system within 20 kilometres of the coast, to shut it down whenever mammals are detected within one kilometre, and to stay out of regions where mammal aggregations are common.

Environmentalists and some academics say that, although there are insufficient data to be certain about the system's effects on marine life, the mitigation measures probably do not go far enough. "I simply do not believe that the Navy has addressed the most fundamental problems," says Joel Reynolds, director of marine mammal protection at the
Natural Resources Defense Council, an environmental group.

Jonathan Gordon, who studies marine mammal acoustics at the University of St Andrews in Scotland, expresses satisfaction that the effects of the military technology have been assessed at all. He points out that France and Britain are developing comparable systems without any public scrutiny. But he remains concerned that the US proposal is based on inadequate information.

Ken Hollingshead, a fisheries biologist at the NMFS, says that the Navy recognizes the need for better information, and will continue to seek it. But Roger Gentry, coordinator of the NMFS acoustics team, says he believes there is enough information available to say with reasonable certainty that the system will cause no significant harm.

Public comment is being invited on the proposed rule, and a final decision will be announced later in the year.

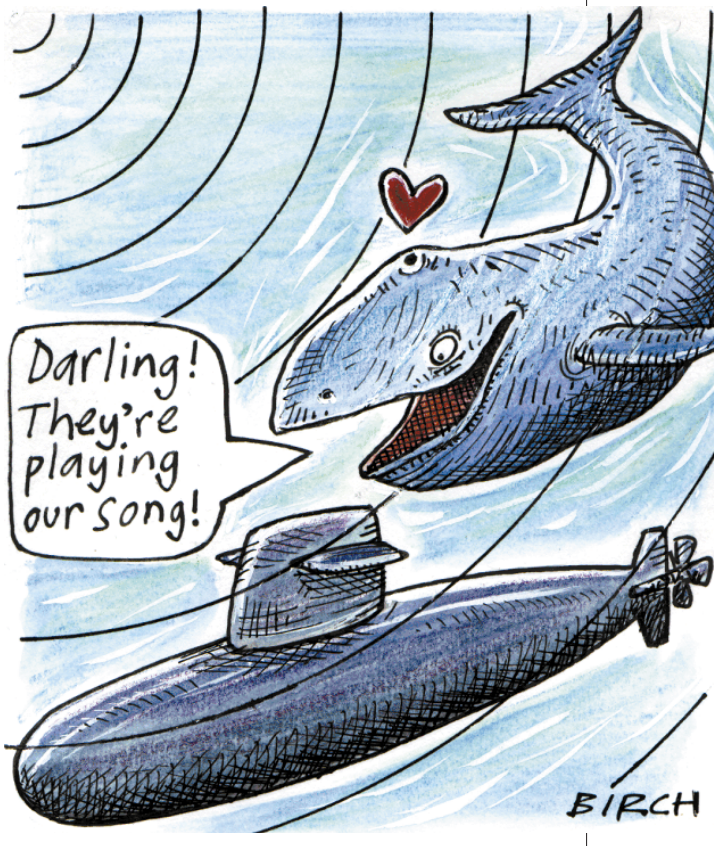

\section{Regulator rebuked over cannabis}

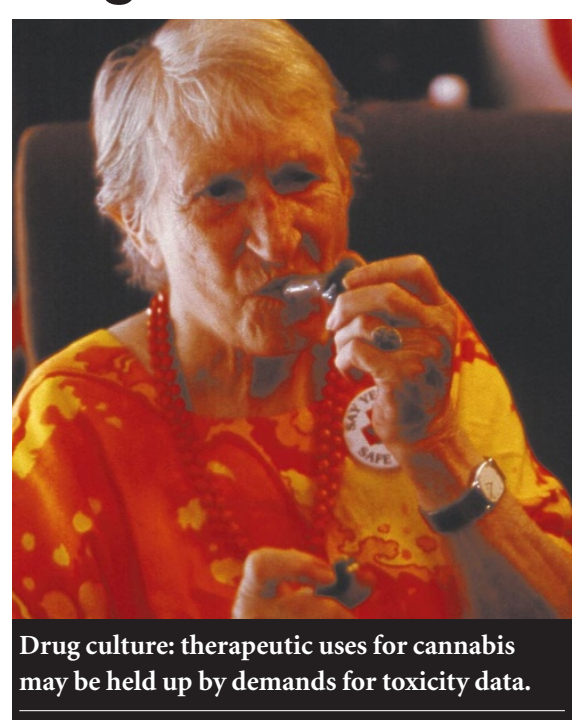

Alison Abbott

The UK Medicines Control Agency (MCA) has come under fire for insisting on full toxicology testing of cannabis extracts in clinical trials, allegedly ignoring

accumulated knowledge of the drug's safety.

The Science and Technology Committee of the House of Lords charges in its latest report that the MCA is "not approaching the question of licensing cannabis-based medicines in a properly balanced way".

A 1998 report from the same committee recommended that doctors be allowed to prescribe cannabis-based medicines. Some patients in Britain with diseases such as multiple sclerosis already treat themselves with cannabis, although it is illegal to do so.

Since the 1998 report, several clinical trials of cannabis have begun in Britain. These include two funded by the Medical Research Council that are comparing an oilbased cannabis extract with the major active component of cannabis.

Trials with pure extracts of different plant varieties of marijuana are also being conducted by the Porton Down-based company GW Pharmaceuticals. Assuming these trials are successful, a product could be available by 2003. But a further delay of two years would be inevitable if long-term toxicology studies are needed, says Geoffrey Guy, the company chairman. He adds that Canadian authorities are not asking for extensive toxicology testing.

Leslie Iversen, professor of pharmacology at the University of Oxford and a scientific advisor to the Lords committee, says the MCA is treating cannabis as if it were an entirely new drug. The agency should be much more flexible in its demands for toxicological data, he says, as experience has shown it to be safe.

"Cannabis was in the pharmacopoeia until the 1940s," adds Lord Perry of Walton, who chaired the Lords' committee. "Asking for two years more testing, as if it were a new compound, is carrying things a bit far." Since the report was written, the MCA has told the Lords committee that it is prepared to review its position.

http://www.parliament.the-stationery-office.co.uk/pa/ Id200001//dselect/Idsctech/50/5001.htm 